University of Wollongong

Research Online

Faculty of Social Sciences - Papers (Archive) Faculty of Arts, Social Sciences \& Humanities

2013

Service based internship training to prepare workers to support the recovery of people with co-occurring substance abuse and mental health disorders

Trevor P. Crowe

University of Wollongong, tcrowe@uow.edu.au

Peter Kelly

University of Wollongong, pkelly@uow.edu.au

James Pepper

Kedesh Rehabilitation Services

Ross McLennan

Kedesh Rehabilitation Services

Frank P. Deane

University of Wollongong, fdeane@uow.edu.au

See next page for additional authors

Follow this and additional works at: https://ro.uow.edu.au/sspapers

Part of the Education Commons, and the Social and Behavioral Sciences Commons

Research Online is the open access institutional repository for the University of Wollongong. For further information contact the UOW Library: research-pubs@uow.edu.au 


\title{
Service based internship training to prepare workers to support the recovery of people with co-occurring substance abuse and mental health disorders
}

\author{
Abstract \\ A repeated measures design was used to evaluate a 12 month on-site counsellor internship programme \\ aimed at training staff to support the recovery needs of people with co-occurring substance use and \\ mental health disorders. Fifty-four interns completed measures of recovery knowledge, attitudes, \\ confidence/competence, as well as identifying significant learning events. Statistically significant \\ improvements were found in terms of attitudes and confidence/competence, and only one recovery \\ knowledge factor, 'roles of self-definition and peers in recovery'. Recovery knowledge at the end of the \\ internship was positively associated with increases in interns' confidence/competence but was not \\ associated with changes in the interns' attitudes. The mentoring, training/feedback and observational \\ elements of the internship programme were highly valued by interns. Competency based learning events \\ were most frequently identified as significant. Strategies to increase self-directed and interpersonally \\ focused learning, and specific personal recovery knowledge in training are discussed.
}

\section{Keywords}

disorders, training, prepare, workers, support, recovery, people, co, service, occurring, internship, substance, abuse, mental, health

\section{Disciplines}

Education | Social and Behavioral Sciences

\section{Publication Details}

Crowe, T. P., Kelly, P., Pepper, J., McLennan, R., Deane, F. P. \& Buckingham, M. (2013). Service Based Internship Training to Prepare Workers to Support the Recovery of People with Co-Occurring Substance Abuse and Mental Health Disorders. International Journal of Mental Health and Addiction, 11 (2), 269-280.

\section{Authors}

Trevor P. Crowe, Peter Kelly, James Pepper, Ross McLennan, Frank P. Deane, and Mark Buckingham 


\section{Running head: Service based internship training}

Service based internship training to prepare workers to support the recovery of people with cooccurring substance abuse and mental health disorders

Trevor P. Crowe ${ }^{1}$, Peter Kelly ${ }^{1}$, James Pepper ${ }^{2}$, Ross McLennan²,

Frank P. Deane ${ }^{1}$, \& Mark Buckingham².

${ }^{1}$ Illawarra Institute for Mental Health, University of Wollongong, NSW, Australia

${ }^{2}$ Kedesh Rehabilitation Services, Wollongong, NSW, Australia

Author for correspondence: Trevor Crowe, Illawarra Institute for Mental Health, School of Psychology, University of Wollongong, Wollongong, NSW 2522, Australia.

Telephone: +61 2 4221 4207, Fax: +61 2 4221 5585, Email: tcrowe@uow.edu.au.

Abstract: 142 words

Total word count: 5790 


\begin{abstract}
A repeated measures design was used to evaluate a 12 month on-site counsellor internship programme aimed at training staff to support the recovery needs of people with co-occurring substance use and mental health disorders. Fifty-four interns completed measures of recovery knowledge, attitudes, confidence/competence, as well as identifying significant learning events. Statistically significant improvements were found in terms of attitudes and confidence/competence, and only one recovery knowledge factor, 'roles of self-definition and peers in recovery'. Recovery knowledge at the end of the internship was positively associated with increases in interns' confidence/competence but was not associated with changes in the interns' attitudes. The mentoring, training/feedback and observational elements of the internship programme were highly valued by interns. Competency based learning events were most frequently identified as significant. Strategies to increase self-directed and interpersonally focused learning, and specific personal recovery knowledge in training are discussed.
\end{abstract}

Keywords

Co-occurring disorders, internship training, workforce development, recovery, competence 
Substance misuse disorders are the most common co-morbidity for people with a mental illness (Brunette, Mueser, and Drake, 2004) and are increasing in prevalence to the point where comorbidity is being considered the norm rather than the exception (Davidson \& White, 2007). Screening suggests the prevalence of co-occurring substance use and mental health disorders (COD) in clients attending residential substance abuse treatment programs in Australia is approximately 71\% (Mortlock, Deane \& Crowe, 2011). Traditionally COD have been treated in parallel or sequentially, however this often results in poor treatment outcomes (Gil-Rivas \& Grella, 2005). More recently, greater support has been found for an integrated approach to treatment, including higher completion rates and lower rates of relapse (Primm et al., 2000; Brunette et al., 2004). Integrated treatment is now seen as the more effective form of treatment for COD (Mueser, Noordsy, Drake, \& Fox, 2003). Integrated treatment approaches bring together both substance use treatment and mental health treatment within the same service or program (Drake et al., 1998). Unfortunately, integrated treatment programs are few and require staff with specialized knowledge and skills in both mental health and substance misuse (Drake et al., 1998).

The term "recovery" has different meanings between mental health, substance misuse and general medical treatment fields (Xie, McHugo, Helmstetter, \& Drake, 2005). While there is some confusion as to what the concept actually entails, there is a current understanding that recovery involves more than just the reduction of symptoms and other deficits associated with a disorder (Xie et al., 2005). Contemporary views of recovery, from mental illness at least, conceptualise recovery in terms of the pursuit of personally meaningful goals and life directions, social and vocational activities, and practicing a preferred identity, not just symptom 
management and relapse prevention (Andresen, Oades, \& Caputi, 2003; Crowe, Deane, Oades, Caputi, \& Morland, 2006; Davidson, O'Connell, Tondora, Lawless, \& Evans, 2005).

Although skills and knowledge of clinical management are required, staff attitudes have also been found to directly impact on the extent to which knowledge is accepted and used (Watson, Maclaren, and Kerr, 2006). Attitudes, knowledge, confidence, and competency are thought to closely associated (Bedregal, O’Connell, \& Davidson, 2006; Eriksen \& McAuliffe, 2003; Siegfried et al., 2007) and are all important components of staff training.

Staff training is more effective if it is based on a variety of adult learning principles (Bryan, Kreuter \& Brownson, 2009). Adults engage most with subjects that are immediately relevant to their job or personal life and but some educational institutions tend to be relatively light on practical application of clinical knowledge and skills (Ferry-Gibson, 2002). Similarly, staff attendance at training workshops can be less than ideal and even for those who do attend, initial increases in knowledge and skills often fail to transfer into routine practice (Deane, Crowe, King, Kavanagh \& Oades, 2006).

In order for adults to learn effectively, a variety of teaching styles are needed in different areas, such as observation, overview of skills, and experience in the application of this learned content (Martin, 2002). Turner (2005) discussed different types of learning, suggesting that when adult trainees are given autonomy and allowed access to learning resources (self-directed learning) while engaging with more structured facilitated training (involved learning), learning outcomes are improved. Similarly, Self Determination Theory (Ryan, Kuhl, \& Deci, 1997; Ryan \& Deci, 2000) proposes that motivation to develop certain behaviours is influenced by overarching needs for competency, relatedness, and autonomy. When an individual has an opportunity to develop 
and experience competence, is able to interact and to relate to others meaningfully, and experiences making choices in his/her life directions s/he will tend to function better and pursue further growth and learning. Further, Cross (2005) highlights the benefits of adult learners being involved in the planning and evaluation of their instruction, giving them some control over their learning environment and the opportunity to teach others.

Internship programs provide in-service training, supervision and mentoring in a way that has the potential to activate many of the abovementioned adult learning principles. They allow individuals to experience a wide range of activities that increase in complexity as they progress through the program, and provide the opportunity to work as a responsible professional whilst being supervised (Holloway \& Roehlke, 1987). Internship programs act as a "gate keeper" between educational development and professional employment (Holloway \& Roehlke, 1987). However, one of the challenges of service based internship programs is to make sure evidence based practices are not ignored in the effort to inculcate interns into existing custom and practice of the service where the internship is based, perhaps restricting self-directed learning (Martin, 2002). Moreover, internship based approaches to training and supervision for recovery support for people with COD are rare, in consequence so is available program evaluation data.

One of the most widely used models in the evaluation of effective training programs is Kirkpatrick’s four-level model (Pidd et al., 2004). This model specifies four levels of evaluation criteria that measure separate, but related, impacts of training. These are: Reaction - referring to the participants' perceptions of the training course; Learning - referring to the improvement in knowledge, skills, and abilities; Behaviour - referring to the change in work practices and behaviours; and Results- referring to the organizational outcomes and returns. 
Kedesh Rehabilitation Services (KRS) is a residential alcohol and other drug rehabilitation centre that aims to cater for the treatment and support needs of people with COD. In addition, the organization has an integrated 12 month counselor internship program, which aims to provide interns with the necessary professional attitudes, skills, knowledge, and confidence needed to work well with clients with COD. The counseling internship is designed to introduce interns into the field in a stepwise fashion, from administration work to psycho-educational group counseling, to case-management and finally individual counseling. The internship combines formal training (2 hours per week) with practical onsite experience (14 hours per week) to effectively support the recovery of people with substance abuse disorders alone or COD. The program utilizes a mixture of direct education and participation and self directed learning and mentoring to allow individuals to build their professional development skills within the field. The program also supports peer-to-peer learning and teaching.

The current study aims to evaluate the KRS counseling internship programme in terms of intern attitudes, knowledge, skills and confidence in working with people with COD. Secondarily the interns' perceptions of specific internship components and experiences are explored alongside interns' reflections on self nominated significant learning events that occur during the internship, which is helpful for informing future workforce development directions for staff working with COD. It is anticipated that as interns progress through the internship program there will be positive improvements in self-reported measures on attitudes, knowledge, skills and confidence when working with clients with COD. It is also expected that where the use of more adult learning principles is acknowledged, the greater the learning outcomes will be noted. 
Method

\section{Participants}

The 54 participants (78.3\% of all eligible interns) consisted of KRS counseling interns, past ( $n=30)$ and present $(n=24)$, who had completed the counseling internship within the last five years. The remaining $21.7 \%$ were either not contactable (18\%), did not consent to participate, or failed to return questionnaires (3.7\%). The majority of KRS interns were aged 18 to 24 years of age (60.5\%), female (71.1\%), current university psychology students (97.4\%) and had no previous training in substance abuse or mental health (63.2\%).

Measures

In order to assess the impact of the KRS internship program, differences between the constructs of attitude, knowledge, confidence, and skills in regard to working with individuals with coexisting substance misuse and mental health problems were examined pre and post-internship. The Recovery Knowledge Inventory (RKI, Bedregal, O’Connell \& Davidson, 2006) was used to measure recovery knowledge; the Co-morbidity Problems Perception Questionnaire (CMPPQ, Watson et al., 2003) used to measure attitudes, the Counselling Practices Questionnaire (CPQ) to measure skills related to working in drug and alcohol and mental health, and the subscale Task Specific Self Esteem from the CMPPQ and the subscale Perceived Need for Extra Training from the CPQ to measure self perceived confidence. The helpfulness of specific learning events and internship programme components was examined via a brief programme components rating scale and a significant learning events survey developed for the purposes of this study.

Co-morbidity Problems Perceptions Questionnaire (CMPPQ) 
The CMPPQ was developed from the Alcohol and Alcohol Problems Perceptions Questionnaire (AAPPQ) and the Mental Health Problems Perceptions Questionnaire (MHPPQ) to measure staff attitudes towards working with individuals with COD. The CMPPQ measures the same subsets of staff attitudes as the AAPPQ, and has established content validity (Watson, Maclaren, Shaw, \& Nolan, 2003). It consists of 33 questions and for this study the Likert scale was reversed from the original so that ratings of $1=$ "strongly disagree" and $7=$ "strongly agree". Thus, higher scores reflected more positive attitudes towards working with clients with COD. The CMPPQ has five factors that account for $77 \%$ of the variance: Factor 1 (Role adequacy) perceptions of their levels of knowledge and skill; Factor 2 (Role support) perceptions of access to specialist workers and/or resources; Factor 3 (Work satisfaction) indicating levels of job satisfaction and motivation to work with these clients; Factor 4 (Esteem) relating to perceptions of task specific self-efficacy; and Factor 5 (Role legitimacy) perceptions of the right to be involved in the treatment of these clients (Watson et al., 2003). The internal consistency of the CMPPQ is good at $\alpha=.90$ for the full scale (Sundgaard et al., 2006).

Recovery Knowledge Inventory (RKI)

The RKI was developed to "assess knowledge and attitudes toward recovery-oriented practices among providers of mental health and substance use treatment and rehabilitation services” (Bedregal, O’Connell \& Davidson, 2006, p. 96). The measure contains 20 items (rated on a Likert type scale, 1= Strongly Disagree, 5= Strongly Agree), designed to reflect personal recovery principles across four domains: 1) roles and responsibilities in recovery, 2) nonlinearity of the recovery process, 3) the roles of self-definition and peers in recovery, and 4) expectations regarding recovery. A principle components analysis involving 144 staff found that $50 \%$ of the variance was accounted for by these 4 factors. Reliability analysis (Cronbach's 
alphas) estimates for the four components were .81, .70, .63, and .47 respectively (Bedregal, O’Connell \& Davidson, 2006).

\section{Counseling Practices Questionnaire (CPQ)}

The Counseling Practices Questionnaire (CPQ) was developed for this study and used to measure KRS interns' perceptions of the importance of specific standards and practices and their level of competence in each practice. The measure contains 29 items which are derived from the National Training Standards for substance use and mental health workers (www.ntis.gov.au), and a review of contemporary research on best practice for substance misuse intervention and treatment. The questionnaire required KRS interns to rate specific standards and practices on a Likert type scale in terms of perceived importance to treatment (1= Not Important, 5= Extremely Important) and confidence in oneself to deliver these practices competently (1= Would not benefit from further training, to $5=\mathrm{A}$ lot of further training required). Example items are, “Engage in effective motivation enhancement strategies (e.g. motivational interviewing)” and “Effectively work through problems, barriers or ruptures in the counselling relationship”.

\section{Helpfulness of programme components}

Three items were derived from specific learning objectives for some of the formal group training sessions that are part of the KRS counsellor internship program. Interns were asked to rate the degree to which they believed components of the internship to be helpful or unhelpful $(1=$ Very Unhelpful, 6 = Very Helpful), including: 1) mentoring by KRS staff, 2) formal intern training groups, 3) observing KRS staff facilitate group treatment sessions for clients.

\section{Significant learning events/experiences survey}


Interns were asked to identify up to three significant learning events/experiences and describe why these events were significantly helpful or hindering in terms of their learning experience. This survey was an adaptation of Robert Elliott's work on Comprehensive Process Analysis (CPA) (e.g., Elliott, 1989; Elliott et al., 1994), providing a process for the interns to reflect on significant events that had occurred throughout their internship.

The universal needs identified in Self Determination Theory (SDT - Deci \& Ryan, 2000) were used to categorize the significant learning events. The theory emphasizes that people have needs for autonomy (desire to self organize experience and behaviour), competence (desire to have an effect on the environment and attain valued outcomes) and relatedness (desire to be connected with others), which provide necessary conditions for learning, growth and integrity (Deci \& Ryan, 2000). The three needs of SDT formed the broad categories in which we could categorize the significant events, as they appeared to be broadly linked with adult learning theory (Bryan, Kreuter \& Brownson, 2009) and had some logical correspondence to the internship learning environment.

All interns' significant learning events were grouped together for examination. Consensus reached by five of the research team indicating that there were a number of repeating event themes which could be categorized under the needs of autonomy, competence and relatedness. In addition to these constructs, several subcategories were derived from each of them, making a total of eleven subcategories. The categories generated under each need were as follows: Autonomy (Initiative, Personal, and Self-Direction), Competence (Critical, Therapy, Professional Conduct, and Knowledge), and Relatedness (Self-identity, Peers, Trainers/Supervisors, and Clients). Each theme was discussed and a set of rules created to guide the categorization of each significant learning event. Each event was assigned to one or more of 
these subcategories. The significant events were coded by two coders independently in terms of the categorisation system. Inter-rater reliability was examined using Cohen's kappa co-efficient (Cohen, 1960) and was found to be good $(\mathrm{k}=.77)$.

\section{Procedures}

Potential participants were informed about the study via telephone, email or directly face to face. Informed consent processes were completed and participants completed written consent and then the questionnaire packages were handed to, posted or emailed to participants, in line with ethics approval from the relevant ethics committee. The self-report questionnaire package was completed twice by each participant. The first questionnaire package instructed interns to reflect back in time and complete the questionnaires "as if" they were just starting their internships. For the new intern group this was given prior to starting the internship. The second internship package instructed past interns to reflect back in time and complete the questionnaires "as if" they had just completed their internships. Current interns also completed the second questionnaire package in terms of their current progress (6 months, 12 months). New interns were contacted and asked to complete the second questionnaire package at 3 months.

\section{Data Analysis}

The quantitative data was collected using the Co-morbidity Problems Perception Questionnaire (CMPPQ), Recovery Knowledge Inventory (RKI), and Counseling Practices Questionnaire (CPQ) contained in the Pre and Post-Internship questionnaire packages. Shapiro-Wilk Normality Test and Levene's Test for Equality of Variances was conducted revealing at least seven subscale measures violated $(\mathrm{p}<.05)$ normality and homogeneity of variance. Due to this violation non-parametric analyses were conducted on the data. 


\section{Results}

Mann-Whitney U Tests were conducted to investigate possible differences on the measures at baseline between current (just completed the internship) and retrospective data obtained from past interns. No significant differences between the two groups were found on any of the measures. Therefore, retrospectively rated questionnaires could legitimately be pooled with current time data to examine the outcomes related to participation in the internship programme.

Changes in attitudes and confidence towards working with individuals with COD

Table I displays the means, standard deviations and results of matched paired Wilcoxon signed rank test for the CMPPQ. The $\mathrm{z}$ values listed indicate that there were significant improvements in the overall CMPPQ scores and across each of the subscales over the 12 months of the internship. Interns' confidence in their own capacity to deliver specific practices competently (i.e., decreases in belief of their need for further training) significantly improved over the course of the internship $(\mathrm{z}=-4.38, \mathrm{p}<.01)$.

Insert Table I here

\section{Changes in recovery knowledge}

Table II displays the means, standard deviations and results of matched paired Wilcoxon signed rank test for the RKI. The $\mathrm{z}$ values listed indicate that there were no significant changes in the overall RKI scores and in each of the subscales, except for 'Roles of self-definition and peers in recovery’. 
Insert Table II here

The relationship between recovery knowledge, attitudes, and confidence

Recovery knowledge at the end of the internship was not associated with changes in interns' attitudes towards working with people with COD $\left(r_{s}=-.08, \mathrm{p}=.57\right)$. However, recovery knowledge was associated with interns' increases in confidence in their capacity to deliver specific practices competently (i.e., decreases in interns' belief of their need for further training CPQ, $\left.r_{s}=-.48, \mathrm{p}<.01\right)$. More positive attitudes towards working with people with COD were associated with increased recognition of the need for further training (i.e., lower confidence in their capacity to deliver specific practices competently, $r_{s}=.51, \mathrm{p}<.01$ ).

Helpfulness of core components of the internship programme

On average, the interns perceived the mentoring by KRS staff throughout the program to be helpful to very helpful in terms of their learning experience as an intern counsellor,

$(M=5.23, S D=1.06)$, intern training sessions $(M=5.17, S D=.92)$, and observing KRS staff facilitate group treatment sessions to clients $(M=5.26, S D=1.01)$ (maximum possible score $=$ 6).

\section{Significant learning events}

The intern identified significant events were in terms of the categorisation system which fell under the broader SDT themes of 'autonomy', 'competence' and 'relatedness'. The frequencies 
of the different types of significant learning events are presented in Appendix I. Types of significant learning events that occurred most frequently were those describing critical incidents (e.g. client suicidality) $($ Critical $=17.0 \%)$, practicing therapy skills $($ Therapy $=15.0 \%)$, and events that challenged the interns' sense of personal or professional identities (Self-Identity = 14.4\%). More broadly the significant events that occurred under the three universal needs of SDT were as follows: Competence (51.6\%), Relatedness (42.5\%), and Autonomy (5.9\%).

\section{Discussion}

The internship programme had a positive impact in terms of increasing interns' positive attitudes towards working with people with COD, and self perceived confidence in their capacity to deliver specific practices competently. Although increased confidence and decreased selfreported need for further training implies an increase in skills for the interns, this needs to be examined further by direct observation skills audits.

Recovery knowledge, which reflects the consumer view of personal recovery (Slade et al., 2008; Onken et al., 2002; Andresen et al., 2003), did not increase significantly over the course of the internship except for the factor 'roles of self definition and peers in recovery' (i.e., knowledge of the need to develop a positive identity in recovery). This may reflect overlap between the contemporary mental health recovery focus regarding redefining identity and engagement of peer support and the focus of the internship programme on this factor. However, it appears that the current internship programme does not sufficiently target a broad enough range of recovery specific content such that there is more comprehensive improvements in interns' recovery knowledge. Intern training programmes aimed at supporting the recovery needs of people with 
COD would benefit from an increased emphasis on reviewing contemporary recovery literature and consumer participation in programme development and intern training.

In spite of the lack of positive change in recovery knowledge over the course of the internship programme, recovery knowledge at the end of the internship was associated with interns' increases in confidence in their capacity to deliver specific practices competently. In the case of recovery knowledge, perhaps the more aware interns are of the responsibilities clients have for their own recovery, and that their own role is not about "fixing" or "changing" clients but rather assisting them to find their own way, the more confident interns may feel in their capacity to provide this support. .

Interestingly, recovery knowledge was not associated with changes in interns' attitudes towards working with people with COD. This is at odds with previous research involving clinicians working in community mental health settings that found that improvements in recovery supporting attitudes were positively associated with increases in recovery knowledge (Crowe et at., 2006). An increase in more explicit training across a broader range of recovery principles that straddle both substance abuse and mental health disorder recovery journeys might see the emergence of a more direct relationship between knowledge and attitudes in substance abuse residential rehabilitation contexts.

More positive attitudes towards working with people with COD were associated with increased recognition of the need for further training (i.e., lower confidence in their capacity to deliver specific practices competently). This could imply that a type of humility or redistribution of power is helpful for working effectively in supporting the recovery journeys of people with COD, inasmuch as positive attitudes include an openness to ongoing learning and feedback and 
allowing the client to teach the clinician how to better support him/her (Miller, Duncan, \& Hubble, 2002). Clearly workers can be confident in their capacity to perform certain tasks competently but in some cases this might be at the cost of working from an empowerment perspective. That is, doing things to people or for people, rather than finding ways to support their autonomy and self-determination of their own recovery (Onken et al, 2002; Oades et al, 2009). It would be worth exploring the relationships between confidence, attitudes and knowledge further within this clinical context after a greater emphasis on recovery knowledge training in the internship occurs.

The evaluation of the main internship programme components suggests that the interns highly valued the mentoring by, and direct observation of, more experienced staff. This was in the context of experienced staff performing treatment related duties as well as in the formal training sessions. These aspects of the programme clearly reflect some of the adult learning principles mentioned earlier in terms of being directly and immediately relevant to the development of clinical skills, and involving demonstration and skills application experience (Martin, 2002). What is interesting is that when interns were asked to identify what their most significant learning events were, the highest frequency categories were "competence" based, followed by "relatedness" based, with relatively few being categorised as reflecting "autonomy" or selfdirected learning. Clearly, mentoring, observing experienced staff and formal training are competency focused, with interactional elements. Further, structure and performance demonstrations and feedback can help interns manage their performance anxiety as they see "how things are done" by experienced staff when, for example, responding to clients who are suicidal or delivering group therapy. However, it appears that the autonomy focused elements of adult learning and self-determination (e.g., self-directedness, showing initiative, exploring 
personal reactions and choices) were less salient or evident in the internship learning experiences of the interns. It may be that the need for competence and interpersonal support and accountability precede the need for self-directed learning in an environment high in crisis and stress management demands.

A significant challenge of training clinical staff within an existing culture and clinical context is the need to balance skills competence, quality of service provision (particular where staff turnover is high), and a commitment to reflective practice while also refining treatment and staff development programmes in response to research and consumer feedback. There are many parallels between the professional development of staff and the recovery journeys of those seeking treatment. One of these parallels is the reference to autonomy and self directedness in both the mental health recovery and adult learning literatures. It may be that if intern training programmes more directly support self-directed learning and directly map staff professional development journeys against clients’ recovery journeys, there might be a greater emphasis on client self-directedness transferred through client-intern interactions (Crowe et al 2011).

\section{Conclusion}

The KRS counsellor internship training programme increases interns' confidence/competence and attitudes in regards to supporting the recovery journeys of people with co-occurring substance abuse and mental health disorders. Developing competence, particularly in the areas of managing critical incidents and providing therapy, are enhanced by the mentoring, training/feedback and observational elements of the internship programme. Increasing autonomy and interpersonally focused learning strategies and specific personal recovery knowledge training, are recommended. 


\section{REFERENCES}

Andresen, R., Oades, L. G., \& Caputi, P. (2003). The experience of recovery from schizophrenia: towards an empirically validated stage model. Australian and New Zealand Journal of Psychiatry, 37, 586-594.

Bedregal, L. E., O'Connell, M., \& Davidson, L. (2006). The recovery knowledge inventory: assessment of mental health staff knowledge and attitudes about recovery. Psychiatric Rehabilitation Journal, 30(2), 96-103.

Brunette, M. F., Mueser, K. T., \& Drake, R. E. (2004). A review of research on residential programs for people with severe mental illness and co-occurring substance use disorders. Drug and Alcohol Review, 23, 471-481.

Bryan, R.L., Kreuter, M.W., \& Brownson, R.C. (2009). Integrating adult learning principles into training for public health practice. Health Promotion Practice, 10, 557-563.

Cross, J. (2005). Adult learning: removing barriers, not creating them. Fine Print, 28(4), 3-6, 21.

Crowe, T. P., Deane, F. P., Oades, L. G., Caputi, P., \& Morland, K. G. (2006). Effectiveness of a collaborative recovery training program in Australia in promoting positive views about recovery. Psychiatric Services, 57(10), 1497-1500.

Crowe, T.P., Oades, L.G., Deane, F.P., Ciarrochi, J., and Williams, V. (2011). Parallel processes in clinical supervision: Implications for coaching mental health practitioners. International Journal of Evidence Based Coaching and Mentoring, 9(2),56-66. 
Davidson, L., O'Connell, M., Tondora, J., Lawless, M., \& Evans, A. C. (2005). Recovery in serious mental illness: a new wine or just a new bottle? Professional Psychology: Research and Practice, 36(5), 480-487.

Davidson, L., \& White, W. L. (2007). The concept of recovery as an organizing principle for integrating mental health and addiction services [Electronic Edition]. Journal of Behavioral Health Services \& Research, 34(2), 109-120.

Deane, F. P., Crowe, T. P., King, R., Kavanagh, D., \& Oades, L. G. (2006). Challenges in implementing evidence-based practice into mental health services. Australian Health Review, 30, 305-309.

Deci, E. L., \& Ryan, R. M. (2000). The "what" and "why" of goal pursuits: Human needs and the self-determination of behavior. Psychological Inquiry, 11, 227-268.

Drake, R. E., Mercer-McFadden, C., Mueser, K. T., McHugo, G. J., \& Bond, G. R. (1998). Review of integrated mental health and substance abuse treatment for patients with dual disorders. Schizophrenia Bulletin, 24(4), 589-608.

Elliott, R. (1989). Comprehensive process analysis: understanding the change process in significant therapy events. In M. J. Packer \& R. B. Addison (Eds.), Entering the Circle: Heremeneutic Investigation in Psychology. Albany, NY: State University of New York Press.

Elliott, R., Shapiro, D. A., Firth-Cozens, J. A., Stiles, W. B., Hardy, G., Llewelyn, S. P., et al. (1994). Comprehensive process analysis of insight events is cognitive-behavioral and 
psychodynamic-interpersonal psychotherapies. Journal of Counseling Psychology, 41, 449-463.

Eriksen, K., \& McAuliffe, G. (2003). A measure of counselor competency. Counselor Education and Supervision, 43(2), 120-133.

Ferry-Gibson, J. (2002). Linking learning styles to communication. Training and Development in Australia, 29(2), 14-16.

Gil-Rivas, V., \& Grella, C. E. (2005). Addictions services: treatment services and service delivery models for dually diagnosed clients: variations across mental health and substance abuse providers. Community Mental Health Journal, 41(3), 251-266.

Holloway, E. \& Roehlke, H.J. (1987). Internship: The Applied Training of a Counseling Psychologist. Counseling Psychologist, 15(2), 205-60.

Martin, G. (2002). Learning styles: the trainers torment? Training and Development in Australia, 29(2), 7-9.

Miller, S. D., Duncan, B. L., \& Hubble, M. A. (2002). Client-directed, outcome-informed clinical work. In F. W. Kaslow, \& J. Lebow (Eds.), Comprehensive Handbook of Psychotherapy: Integrative/Eclectic (Vol. 4, pp. 185-212). New York: Wiley.

Mortlock, K. S., Deane, F. P., \& Crowe, T. P. (2011). Screening for mental disorder comorbidity in Australian alcohol and other drug residential treatment settings. Journal of Substance Abuse Treatment, 40, 397-404.

Mueser, K. T., Noordsy, D.L., Drake, R. E., \& Fox, L. (2003). Integrated treatment for dual disorders: A guide to effective practice. The Guildford Press: NY. 
National Training Information Service (2007). Australian competency standards for alcohol, other drug and mental health workers. Retrieved March 24th, 2007, from http://www.ntis.gov.au

Oades, L.G., Crowe, T.P. \& Nguyen, M. (2009). 'Leadership coaching transforming mental health systems from the inside out: The Collaborative Recovery Model as person-centred strengths based coaching psychology’. International Coaching Psychology Review, 4(1), 25-36.

Onken S., Dumont J., Ridgway P., Dornan D. \& Ralph R.O. (2002). Mental Health Recovery: What Helps What Hinders? A National Research Project for the Development of Recovery Facilitating System Performance Indicators. Alexandria, VA: National Technical Assistance Center for State Mental Health Planning and the National Association of State Mental Health Program Directors.

Pidd, K., Freeman, T., Skinner, N., Addy, D., Shoobridge, J., \& Roche, A.M. (2004). From training to work practice change: An examination of factors influencing training transfer in the alcohol and other drug field. Canberra: Department of Health and Ageing.

Primm, A. B., Tzolova-Iontchev, I., \& Taylor, C. M. (2000). An integrated approach for dually diagnosed patients in a substance abuse treatment program: case presentation. Substance Abuse, 21(2), 121-126.

Ryan, R. M., \& Deci, E. L. (2000). Self-determination theory and the facilitation of intrinsic motivation, social development, and well-being. American Psychologist, 55, 68-78. 
Siegfried, N., Ferguson, J., Cleary, M., Walter, G., \& Rey, J. M. (2007). Experience, knowledge and attitudes of mental health staff regarding patients' problematic drug and alcohol use. Australian and New Zealand Journal of Psychiatry, 33(2), 267-273.

Slade, M., Amering, M., \& Oades, L. (2008). 'Recovery: an international perspective'. Epidemiologia e Psichiatria Sociale, 17(2), 128-137.

Sundgaard, T. Substance misuse treatment staff attitudes regarding working with clients who have complex mental health and substance misuse problems. Unpublished thesis, University of Wollongong, Australia.

Turner, T. (2005). Encouraging self-directed learning by spiraling through a course. Paper presented at the Higher Education Research and Development Society of Australasia Conference, Sydney.

Watson, H. E., Maclaren, W., \& Kerr, S. (2006). Staff attitudes towards working with drug users: development of the drug problems perceptions questionnaire. Addiction, 102, 206-215.

Watson, H. E., Maclaren, W., Shaw, F., \& A, N. (2003). Measuring staff attitudes to people with drug problems: the development of a tool. Edinburgh: Effective Interventions Unit, Scottish Executive Drug Misuse Research Programme.

Xie, H., McHugo, G. J., Helmstetter, B. S., \& Drake, R. E. (2005). Three-year recovery outcomes for long-term patients with co-occurring schizophrenic and substance use disorders. Schizophrenia Research, 75(2-3), 337-348. 
Table I. Changes in CMPPQ scores

Pre-internship Mean 12 months Mean z-value p-value

(std. dev.) (std. dev.)

\begin{tabular}{|c|c|c|c|c|}
\hline Role Adequacy & $3.58(1.04)$ & $5.24(.65)$ & -6.35 & $.00 * *$ \\
\hline Role Support & $5.24(1.36)$ & $6.49(.58)$ & -5.33 & $.00 * *$ \\
\hline Work & $4.50(.99)$ & $4.87(1.01)$ & -4.05 & $.00 * *$ \\
\hline \multicolumn{5}{|l|}{ Satisfaction } \\
\hline Task Self & $3.36(1.25)$ & $5.71(.90)$ & -6.10 & $.00 * *$ \\
\hline \multicolumn{5}{|l|}{ Efficacy } \\
\hline Role Legitimacy & $3.65(1.43)$ & $5.67(.89)$ & -5.94 & $.00 * *$ \\
\hline CMPPQ Total & $20.33(4.64)$ & 27.99 (2.67) & -6.34 & $.00 * *$ \\
\hline
\end{tabular}


Table II. Changes in recovery knowledge over time.

Pre-internship 12 months Mean $\quad$ z-value $\quad$ p-value Mean

(std. dev.)

(std. dev.)

\begin{tabular}{lcccc}
\hline Roles and responsibilities & $2.95(.80)$ & $2.88(1.14)$ & -.71 & .48 \\
in recovery & & & & \\
Non-linearity of the & $2.98(.70)$ & $2.94(.79)$ & -.43 & .67 \\
recovery process & & & & \\
Roles of self-definition & $3.77(.46)$ & $4.13(.36)$ & -4.48 & $.00^{* *}$ \\
and peers in recovery & & & & \\
Expectations regarding & $3.16(.76)$ & $3.01(.74)$ & -1.07 & .29 \\
recovery & & & & .70 \\
RKI Total & & & & \\
\end{tabular}

(significant at $* .05,{ }^{* *} .01$ ) 
Appendix I Frequency of Significant Learning Events (SLE)

SLE Category Frequency

(SDT needs type)

(\%)

Example of Intern Significant Events

Critical (C)

17.0

I was doing an ICF and the client stated that he was feeling $\underline{\text { suicidal. Talked him through it and called police }}$

For me starting case management was an extremely

Therapy (C)

15.0

important step. Seeing clients one on one first time was

extremely helpful before actually going on to one on one

counselling

Comforted a distressed client who thought he was going back

Self-Identity (R)

14.4 to gaol. Made me realise how far I had come and my

capabilities when dealing with stressful situations

Counselling client disclosing past trauma to me during a

Clients (R)

11.1 counselling session. My client disclosed this for the first time

to any mental health professional

$\underline{\text { Ex client came to my house. I told staff and documented this, }}$

Professional Conduct

9.8

then cut off association with ex client. It was a difficult

situation to be put in and tested my ability to maintain

confidentiality

Knowledge (C)

9.8 Learning how to do the first session with counselling clients. 
This process which was done in training was extremely helpful

I attended my first session and the KRS team were involved

Peers (R)

9.1 in supporting and assisting me with preparing for the first session.

Trainers/Supervisors (R)

7.8 trainer was so good at what she did. She showed all the skills I thought a good therapist would have

There was a new client in the house who had isolated themselves. They were watching TV and $\underline{I \text { went in and }}$

Initiative (A)

3.3 watched TV with them and talked to them. From this the client opened up

Personal (A) 2.5

A client got discharged that I liked. It was the first time I'd been disappointed with a decision made by Kedesh

Self Direction (A) .65

Worked through personal issues with a client who was bagging me out to other clients, and used it as a therapeutic exercise

Note: Self Determination Theory universal needs categories (A) is Autonomy, (R) is Relatedness, and (C) is Competency 